\title{
Weak and Strong Convergence of an Algorithm for the Split Common Fixed-Point of Asymptotically Quasi-Nonexpansive Operators
}

\author{
Yazheng Dang ${ }^{1,2}$ and Yan Gao ${ }^{1}$ \\ ${ }^{1}$ School of Management, University of Shanghai for Science and Technology, Shanghai 200093, China \\ ${ }^{2}$ Henan Polytechnic University, Jiaozuo 454000, China \\ Correspondence should be addressed to Yazheng Dang; jgdyz@163.com
}

Received 28 June 2013; Revised 10 October 2013; Accepted 24 October 2013

Academic Editor: Joao B. R. Do Val

Copyright (c) 2013 Y. Dang and Y. Gao. This is an open access article distributed under the Creative Commons Attribution License, which permits unrestricted use, distribution, and reproduction in any medium, provided the original work is properly cited.

Inspired by the Moudafi (2010), we propose an algorithm for solving the split common fixed-point problem for a wide class of asymptotically quasi-nonexpansive operators and the weak and strong convergence of the algorithm are shown under some suitable conditions in Hilbert spaces. The algorithm and its convergence results improve and develop previous results for split feasibility problems.

\section{Introduction}

Fixed-point problem is a classical problem in nonlinear analysis and it has application in a wide spectrum of fields such as economics, physics, and applied sciences. In this paper, We are concerned with the split common fixed point problem (SCFP). In fact, the SCFP is an extension of the split feasibility problem (SFP) and the convex feasibility problem (CFP), see [1]. The CFP and SCFP have many applications such as approximation theory [2], image reconstruction, radiation therapy $[3,4]$, and control [5]. The SFP in finitedimensional space was first introduced by Censor and Elfving [6] for modeling inverse problems, which arise from phase retrievals, and in medical image reconstruction [7]. Recently, it has been found that the SFP can also be used in various disciplines such as image restoration, computer tomograph, and radiation therapy treatment planning $[8,9]$. The SFP in an infinite-dimensional Hilbert space can be found in [10-13].

Throughout this paper, we assume that both $H_{1}$ and $H_{2}$ are real Hilbert spaces, " $\rightarrow$ " and " $\rightarrow$ " denote strong and weak convergence, respectively, Fix $(T)$ denotes the set of the fixed points of an operator $T$, that is, and Fix $(T):=\{x \mid x=T(x)\}$. Let $U: H_{1} \rightarrow H_{1}$ and $T: H_{2} \rightarrow H_{2}$ be two asymptotically quasi-nonexpansive mappings with nonempty fixed-point sets $\operatorname{Fix}(U)=C$ and $\operatorname{Fix}(T)=Q$, respectively. The split common fixed point problem for operators $U$ and $T$ is to find

$$
x^{*} \in C \text { such that } A x^{*} \in Q \text {, }
$$

where $A: H_{1} \rightarrow H_{2}$ is bounded linear. Denote the solution set of the two-operator SCFP by

$$
\Gamma=\{y \in C \mid A y \in Q\} .
$$

The split common fixed point problem for quasinonexpansive mapping in the setting of Hilbert space was first introduced and studied by Moudafi [14]. However, the algorithm presented in [14] has only weak convergence. The purpose of this paper is to propose an algorithm of split common fixed point problem for asymptotically quasi-nonexpanding operator which includes the quasi-nonexpansive mapping and the weak and strong convergence of the algorithm are shown under some suitable conditions in Hilbert spaces. The algorithm and the convergence results improve and develop previously discussed split feasibility problems.

The paper is organized as follows. In Section 2, we recall some preliminaries. In Section 3, we present an algorithm and show its weak convergence and strong convergence. Section 4 gives some concluding remarks. 


\section{Preliminaries}

Recall that a mapping $T: H \rightarrow H$ is said to be nonexpansive if

$$
\|T(x)-T(y)\| \leq\|x-y\|, \quad(x, y) \in H \times H .
$$

A mapping $T$ is called asymptotically nonexpansive if there exists a sequence $\left\{l_{k}\right\} \subset[1, \infty)$ with $l_{k} \rightarrow 1$ as $k \rightarrow \infty$ such that, for all $(x, y) \in H \times H$,

$$
\left\|T^{k}(x)-T^{k}(y)\right\| \leq l_{k}\|x-y\|, \quad \forall k \geq 1 .
$$

A mapping $T$ is called quasi-nonexpansive if for all $(x, z) \in H \times F(T)$

$$
\|T(x)-z\| \leq\|x-z\| .
$$

A mapping $T$ is called asymptotically quasi-nonexpansive if there exists a sequence $\left\{l_{k}\right\} \subset[1, \infty)$ with $l_{k} \rightarrow 1$ as $k \rightarrow$ $\infty$ such that, for all $(x, z) \in H \times \operatorname{Fix}(T)$,

$$
\left\|T^{k}(x)-z\right\| \leq l_{k}\|x-z\|, \quad \forall k \geq 1 .
$$

A mapping $T$ is said to be uniformly $L$-Lipschitzian if there exists a constant $L>0$ such that for all $(x, y) \in H \times H$,

$$
\left\|T^{k}(x)-T^{k}(y)\right\| \leq L\|x-y\|, \quad \forall k \geq 1 .
$$

A mapping $T$ is said to be semicompact if for any bounded sequence $\left\{x^{k}\right\} \subset H$ with $\lim _{k \rightarrow \infty}\left\|x^{k}-T x^{k}\right\|=0$ there exists a subsequence $\left\{x^{k_{p}}\right\}$ of $\left\{x^{k}\right\}$ such that $\left\{x^{k_{p}}\right\}$ converges strongly to a point $x^{*} \in H$.

Let $E$ be a Banach space. A mapping $T: E \rightarrow E$ is said to be demiclosed at origin, if for any sequence $\left\{x^{k}\right\} \subset E$ with $x^{k} \rightarrow x^{*}$ and $\left\|(I-T) x^{k}\right\| \rightarrow 0, x^{*}=T\left(x^{*}\right)$.

Lemma 1. Let $T: H \rightarrow H$ be asymptotically quasinonexpansive and set $T_{\alpha}^{k}:=(1-\alpha) I+\alpha T^{k}$ for $\alpha \in(0,1]$. Then, for any $z \in \operatorname{Fix}(T)$ and $x \in H$, one has the following:

(1) $\left\langle x-T^{k}(x), x-z\right\rangle \geq(1 / 2)\left\|x-T^{k}(x)\right\|^{2}-\left(\left(l_{k}^{2}-\right.\right.$ 1)/2) $\left\|x^{k}-z\right\|^{2}$

(2) $\left\langle x-T^{k}(x), z-T^{k}(x)\right\rangle \leq(1 / 2)\left\|x-T^{k}(x)\right\|^{2}+\left(\left(l_{k}^{2}-\right.\right.$ 1)/2) $\left\|x^{k}-z\right\|^{2}$

(3) $\left\|T_{\alpha}^{k}(x)-z\right\|^{2} \leq\left[1+\alpha\left(l_{k}^{2}-1\right)\right]\|x-z\|^{2}-\alpha(1-\alpha) \| x-$ $T^{k}(x) \|$;

(4) $\left\langle x-T_{\alpha}^{k}(x), x-z\right\rangle \geq(\alpha / 2)\left\|x-T^{k}(x)\right\|^{2}-\left(\left(\alpha\left(l_{k}^{2}-\right.\right.\right.$ 1))/2) $\left\|x^{k}-z\right\|^{2}$.

Lemma 2 (see [15]). Suppose $\left\{a_{k}\right\}$ is a sequence of nonnegative real numbers such that

$$
a_{k+1} \leq\left(1+\delta_{k}\right) a_{k}+b_{k}, \quad k \geq 0
$$

if (i) $\sum_{k=0}^{\infty} \delta_{k}<\infty$ and (ii) $\sum_{k=1}^{\infty} b_{k}<\infty$. Then, $\lim _{k \rightarrow \infty} a_{k}$ exists. In particular, if $\left\{a_{k}\right\}$ has a subsequence which converges strongly to zero, then $\lim _{k \rightarrow \infty} a_{k}=0$.

\section{The Algorithm and Its Asymptotic Convergence}

We now give a description of an algorithm.

Algorithm 3. Initialization: let $x^{0} \in H_{1}$ be arbitrary.

Iterative step: for $k \in N$, set $u^{k}=x^{k}+\gamma A^{T}\left(T^{k}-I\right) A\left(x^{k}\right)$, let

$$
x^{k+1}=\left(1-\alpha_{k}\right) u^{k}+\alpha_{k} U^{k}\left(u^{k}\right), \quad k \in N,
$$

where $\alpha_{k} \in[\alpha, 1-\alpha], \alpha \in(0,1)$, and $\gamma \in(0,1 / \lambda), \lambda=\|A\|^{2}$.

In what follows, we establish the weak convergence and strong convergence of Algorithm 3.

Lemma 4 (Opial [16]). Let $H$ be a Hilbert space and let $\left\{x^{k}\right\}$ be a sequence in $H$ such that there exists a nonempty set $S \subset H$ satisfying the following.

(1) For every $x^{*}, \lim _{k}\left\|x^{k}-x^{*}\right\|$ exists.

(2) Any weak cluster point of the sequence $\left\{x^{k}\right\}$ belongs to S.

Then, there exists $z \in S$ such that $\left\{x^{k}\right\}$ weakly converges to $z$.

Theorem 5. Let $U: H_{1} \rightarrow H_{1}$ and $T: H_{2} \rightarrow H_{2}$ be two asymptotically quasi-nonexpansive operators with nonempty $\operatorname{Fix}(U)=C$ and $\operatorname{Fix}(T)=Q$. Assume that $U-I$ and $T-I$ are demiclosed at 0 and $\Gamma \neq \emptyset, \sum_{k=1}^{\infty}\left(l_{k}^{2}-1\right)<\infty$, and $T$ and $U$ are uniformly L-Lipschitzian. Then,

(I) any sequence $\left\{x^{k}\right\}$ generated by Algorithm 3 converges weakly to a point $x^{*} \in \Gamma$;

(II) if $U$ is also semi-compact, then both $\left\{x^{k}\right\}$ and $\left\{u^{k}\right\}$ generated by Algorithm 3 converge strongly to a point $x^{*} \in \Gamma$.

Proof. First, we prove that for each $z \in \Gamma, \lim _{k \rightarrow \infty}\left\|x^{k}-z\right\|$ and $\lim _{k \rightarrow \infty}\left\|u^{k}-z\right\|$ exist. Also $\lim _{k \rightarrow+\infty}\left\|\left(T^{k}-I\right)\left(A x^{k}\right)\right\|=0$ and $\lim _{k \rightarrow+\infty}\left\|\left(U^{k}\left(u^{k}\right)-u^{k}\right)\right\|=0$.

By using (1) in Lemma 1, from (9) we obtain

$$
\begin{aligned}
\left\|x^{k+1}-z\right\|^{2}= & \left\|\left(1-\alpha_{k}\right) u^{k}+\alpha_{k} U^{k}\left(u^{k}\right)-z\right\|^{2} \\
\leq & {\left[1+\alpha_{k}\left(l_{k}^{2}-1\right)\right]\left\|u^{k}-z\right\|^{2} } \\
& -\alpha_{k}\left(1-\alpha_{k}\right)\left\|u^{k}-U^{k}\left(u^{k}\right)\right\|^{2} .
\end{aligned}
$$

By deducing, it follows that

$$
\begin{aligned}
\left\|u^{k}-z\right\|^{2}= & \left\|x^{k}+\gamma A^{T}\left(T^{k}-I\right)\left(A x^{k}\right)-z\right\|^{2} \\
= & \left\|x^{k}-z\right\|^{2}+\gamma^{2}\left\|A^{T}\left(T^{k}-I\right)\left(A x^{k}\right)\right\|^{2} \\
& +2 \gamma\left\langle x^{k}-z, A^{T}\left(T^{k}-I\right)\left(A x^{k}\right)\right\rangle \\
\leq & \left\|x^{k}-z\right\|^{2}+\lambda \gamma^{2}\left\|\left(T^{k}-I\right)\left(A x^{k}\right)\right\|^{2} \\
& +2 \gamma\left\langle A x^{k}-A z,\left(T^{k}-I\right)\left(A x^{k}\right)\right\rangle
\end{aligned}
$$


that is,

$$
\begin{aligned}
\left\|u^{k}-z\right\|^{2} \leq & \left\|x^{k}-z\right\|^{2}+\lambda \gamma^{2}\left\|\left(T^{k}-I\right)\left(A x^{k}\right)\right\|^{2} \\
& +2 \gamma\left\langle A x^{k}-A z,\left(T^{k}-I\right)\left(A x^{k}\right)\right\rangle .
\end{aligned}
$$

Setting $\theta:=2 \gamma\left\langle A x^{k}-A z,(T-I)\left(A x^{k}\right)\right\rangle$ and using (1) of Lemma 1, we obtain

$$
\begin{aligned}
\theta= & 2 \gamma\left\langle A x^{k}-A z,\left(T^{k}-I\right)\left(A x^{k}\right)\right\rangle \\
= & 2 \gamma\left\langle A x^{k}-A z+\left(T^{k}-I\right)\left(A x^{k}\right)\right. \\
& \left.\quad-\left(T^{k}-I\right)\left(A x^{k}\right),\left(T^{k}-I\right)\left(A x^{k}\right)\right\rangle \\
= & 2 \gamma\left(\left\langle A x^{k}-A z,(T-I)\left(A x^{k}\right)\right\rangle-\left\|(T-I)\left(A x^{k}\right)\right\|^{2}\right) \\
\leq & 2 \gamma\left(\frac{1}{2}\left\|\left(T^{k}-I\right)\left(A x^{k}\right)\right\|^{2}+\frac{l_{k}^{2}-1}{2}\left\|A x^{k}-A z\right\|^{2}\right. \\
\quad & \left.\quad\left\|\left(T^{k}-I\right)\left(A x^{k}\right)\right\|^{2}\right) \\
= & -\gamma\left\|\left(T^{k}-I\right)\left(A x^{k}\right)\right\|^{2}+\gamma \lambda\left(l_{k}^{2}-1\right)\left\|x^{k}-z\right\|^{2} .
\end{aligned}
$$

The key inequality mentioned above, combined with (12), yields

$$
\begin{aligned}
\left\|u^{k}-z\right\|^{2} \leq & \left(1+\gamma \lambda\left(l_{k}^{2}-1\right)\right)\left\|x^{k}-z\right\|^{2} \\
& -\gamma(1-\lambda \gamma)\left\|\left(T^{k}-I\right)\left(A x^{k}\right)\right\|^{2} .
\end{aligned}
$$

Substituting (14) into (10) yields

$$
\begin{aligned}
\left\|x^{k+1}-z\right\|^{2} & \\
\leq & {\left[1+\alpha_{k}\left(l_{k}^{2}-1\right)\right] } \\
& \times\left[\left(1+\gamma \lambda\left(l_{k}^{2}-1\right)\right)\left\|x^{k}-z\right\|^{2}\right. \\
& \left.-\gamma(1-\lambda \gamma)\left\|\left(T^{k}-I\right)\left(A x^{k}\right)\right\|^{2}\right] \\
& -\alpha_{k}\left(1-\alpha_{k}\right)\left\|u^{k}-U^{k}\left(u^{k}\right)\right\| \\
= & {\left[1+\left(\alpha_{k}+\gamma \lambda\right)\left(l_{k}^{2}-1\right)+\alpha_{k} \gamma \lambda\left(l_{k}^{2}-1\right)^{2}\right]\left\|x^{k}-z\right\|^{2} } \\
& -\left[1+\alpha_{k}\left(l_{k}^{2}-1\right)\right] \gamma(1-\lambda \gamma)\left\|\left(T^{k}-I\right)\left(A x^{k}\right)\right\|^{2} \\
& -\alpha_{k}\left(1-\alpha_{k}\right)\left\|u^{k}-U^{k}\left(u^{k}\right)\right\|^{2} \\
= & {\left[1+\delta_{k}\right]\left\|x^{k}-z\right\|^{2}-\left[1+\alpha_{k}\left(l_{k}^{2}-1\right)\right] \gamma(1-\lambda \gamma) } \\
& \times\left\|\left(T^{k}-I\right)\left(A x^{k}\right)\right\|^{2} \\
& -\alpha_{k}\left(1-\alpha_{k}\right)\left\|u^{k}-U^{k}\left(u^{k}\right)\right\|^{2}+b_{k},
\end{aligned}
$$

where $\delta_{k}=\left(\alpha_{k}+\gamma \lambda\right)\left(l_{k}^{2}-1\right)+\alpha_{k} \gamma \lambda\left(l_{k}^{2}-1\right)^{2}, b_{k}=0$. Since $\sum_{k=1}^{\infty}\left(l_{k}^{2}-1\right)<\infty$, we have $\sum_{k=1}^{\infty} \delta_{k}<\infty$, From Lemma 1, it follows that $\lim _{k \rightarrow \infty}\left\|x^{k}-z\right\|$ exists. By the virtue of (14), we know that $\lim _{k \rightarrow \infty}\left\|u^{k}-z\right\|$ exists. Therefore, from (15), we have

$$
\begin{aligned}
{[1+} & \left.\alpha_{k}\left(l_{k}^{2}-1\right)\right] \gamma(1-\lambda \gamma)\left\|\left(T^{k}-I\right)\left(A x^{k}\right)\right\|^{2} \\
& +\alpha_{k}\left(1-\alpha_{k}\right)\left\|u^{k}-U^{k}\left(u^{k}\right)\right\|^{2} \\
\leq & \left\|x^{k}-z\right\|^{2}-\left\|x^{k+1}-z\right\|^{2} \\
& -\left(\alpha_{k}+\gamma \lambda\right)\left(l_{k}^{2}-1\right) \\
& +\alpha_{k} \gamma \lambda\left(l_{k}^{2}-1\right)^{2}\left\|x^{k}-z\right\|^{2} \longrightarrow 0 .
\end{aligned}
$$

By the assumptions on $l_{k}$ and $\alpha_{k}$, we get

$$
\begin{aligned}
& \lim _{k \rightarrow+\infty}\left\|\left(T^{k}-I\right)\left(A x^{k}\right)\right\|=0, \\
& \lim _{k \rightarrow+\infty}\left\|\left(U^{k}\left(u^{k}\right)-u^{k}\right)\right\|=0 .
\end{aligned}
$$

Step 1. Now, we prove that $\lim _{k \rightarrow \infty}\left\|x^{k+1}-x^{k}\right\|=0$ and $\lim _{k \rightarrow \infty}\left\|u^{k+1}-u^{k}\right\|=0$. As a matter of a fact, it follows from (9) that

$$
\begin{aligned}
& \left\|x^{k+1}-x^{k}\right\| \\
& =\left\|\left(1-\alpha_{k}\right) u^{k}+\alpha_{k} U^{k}\left(u^{k}\right)-x^{k}\right\| \\
& =\left\|\left(1-\alpha_{k}\right)\left(x^{k}+\gamma A^{T}\left(T^{k}-I\right) A x^{k}\right)+\alpha_{k} U^{k}\left(u^{k}\right)-x^{k}\right\| \\
& =\left\|\left(1-\alpha_{k}\right) \gamma A^{T}\left(T^{k}-I\right) A x^{k}+\alpha_{k}\left(U^{k}\left(u^{k}\right)-x^{k}\right)\right\| \\
& =\|\left(1-\alpha_{k}\right) \gamma A^{T}\left(T^{k}-I\right) A x^{k} \\
& \quad+\alpha_{k}\left(U^{k}\left(u^{k}\right)-u^{k}\right)+\alpha_{k}\left(u^{k}-x^{k}\right) \| \\
& =\|\left(1-\alpha_{k}\right) \gamma A^{T}\left(T^{k}-I\right) A x^{k} \\
& \quad+\alpha_{k}\left(U^{k}\left(u^{k}\right)-u^{k}\right)+\alpha_{k} \gamma A^{T}\left(T^{k}-I\right) A x^{k} \| \\
& =\left\|\gamma A^{T}\left(T^{k}-I\right) A x^{k}+\alpha_{k}\left(U^{k}\left(u^{k}\right)-u^{k}\right)\right\| .
\end{aligned}
$$

In view of (17), we have that

$$
\lim _{k \rightarrow \infty}\left\|x^{k+1}-x^{k}\right\|=0
$$


Similarly, it follows from (9), (17), and (19) that

$$
\begin{aligned}
& \left\|u^{k+1}-u^{k}\right\| \\
& =\|\left(x^{k+1}+\gamma A^{T}\left(T^{k+1}-I\right) A x^{k+1}\right) \\
& \quad-\left(x^{k}+\gamma A^{T}\left(T^{k}-I\right) A x^{k}\right) \| \\
& \leq\left\|x^{k+1}-x^{k}\right\|+\gamma\left\|A^{T}\left(T^{k+1}-I\right) A x^{k+1}\right\| \\
& \quad+\gamma\left\|A^{T}\left(T^{k}-I\right) A x^{k}\right\| \longrightarrow 0, \quad(k \longrightarrow \infty) .
\end{aligned}
$$

Step 2. We prove that $\lim _{k \rightarrow \infty}\left\|A x^{k}-T\left(A x^{k}\right)\right\|=0$ and $\lim _{k \rightarrow \infty}\left\|u^{k}-U\left(u^{k}\right)\right\|=0$. Setting $\eta_{k}:=\left\|u^{k}-U^{k}\left(u^{k}\right)\right\|$, since $U$ is uniformly $L$-Lipschitzian continuous, it follows from (14) and (17) that

$$
\begin{aligned}
\left\|u^{k}-U\left(u^{k}\right)\right\| \leq & \left\|u^{k}-U^{k}\left(u^{k}\right)\right\|+\left\|U^{k}\left(u^{k}\right)-U\left(u^{k}\right)\right\| \\
\leq & \eta_{k}+L\left\|U^{k-1}\left(u^{k}\right)-u^{k}\right\| \\
\leq & \eta_{k}+L\left(\left\|U^{k-1}\left(u^{k}\right)-U^{k-1}\left(u^{k-1}\right)\right\|\right. \\
& \left.+\left\|U^{k-1}\left(u^{k-1}\right)-u^{k}\right\|\right) \\
\leq & \eta_{k}+L^{2}\left\|u^{k}-u^{k-1}\right\| \\
& +L\left(\left\|U^{k-1}\left(u^{k-1}\right)-u^{k-1}\right\|+\left\|u^{k-1}-u^{k}\right\|\right) \\
\leq & \eta_{k}+L(L+1)\left\|u^{k}-u^{k-1}\right\| \\
& +L \eta_{k-1} \longrightarrow 0, \quad(k \longrightarrow \infty) ;
\end{aligned}
$$

in other words,

$$
\lim _{k \rightarrow \infty}\left\|u^{k}-U\left(u^{k}\right)\right\|=0 .
$$

Similarly, we have

$$
\lim _{k \rightarrow \infty}\left\|A x^{k}-T\left(A x^{k}\right)\right\|=0 .
$$

Step 3. Finally, we prove that $x^{k} \rightarrow x^{*}$ and $x^{k} \rightarrow x^{*}$, where $x^{*} \in \Gamma$. Denote by $x^{*}$ a weak-cluster point of $\left\{x^{k}\right\}$, and denote by $\left\{x^{k_{\sigma}}\right\}$ a subsequence of $\left\{x^{k}\right\}$. Obviously,

$$
w-\lim _{\sigma} y^{k_{\sigma}}=w-\lim _{\sigma} x^{k_{\sigma}}=x^{*} .
$$

Then, from (23) and the demiclosedness of $T-I$ at 0 , we obtain

$$
T\left(A x^{*}\right)=A x^{*}
$$

it follows that, $A x^{*} \in Q$.

Noticing $u^{k}=x^{k}+\gamma A^{*}(T-I)\left(A x^{k}\right)$, it follows that $w-$ $\lim _{\sigma} u^{k_{\sigma}}=x^{*}$. By the demiclosedness of $U-I$ at 0 , we have

$$
U\left(x^{*}\right)=x^{*} .
$$

Hence, $x^{*} \in C$, and therefore $x^{*} \in \Gamma$.
Since there is no more than one weak cluster point, the weak convergence of the whole sequence $\left\{x^{k}\right\}$ follows by applying Lemma 4 with $S=\Gamma$.

The Proof of Conclusion (II). Since $U$ is semi-compact, it follows from (22) that there exists a subsequence $\left\{u^{k_{h}}\right\}$ of $\left\{u^{k}\right\}$ such that $\left\{u^{k_{h}}\right\} \rightarrow u^{*} \in H$ (some point in $H$ ). Since $x^{k}=u^{k}-\gamma A^{T}\left(T^{k}-I\right) A\left(x^{k}\right)\left\{u^{k_{h}}\right\} \rightarrow x^{*}$, this implies that $x^{*}=u^{*}$. Therefore, $\left\{u^{k_{h}}\right\} \rightarrow x^{*} \in \Gamma$ as $h \rightarrow \infty$. Since for any $z \in \Gamma, \lim _{k \rightarrow \infty}\left\|x^{k}-z\right\|$ and $\lim _{k \rightarrow \infty}\left\|u^{k}-z\right\|$ exist, we know that $\lim _{k \rightarrow \infty}\left\|x^{k}-x^{*}\right\|=\lim _{k \rightarrow \infty}\left\|u^{k}-x^{*}\right\|=0$. This implies that $\left\{x^{k}\right\}$ and $\left\{u^{k}\right\}$ both converge strongly to a point $x^{*} \in \Gamma$. The proof is completed.

\section{Concluding Remarks}

In this paper, we have proposed an algorithm for solving the SCFP in the wide class of asymptotically quasi-nonexpansive operators and obtained its weak and strong convergence in general Hilbert spaces in a new way. Next, we will improve the algorithm to solve the multiple split common fixed point problem in infinite Hilbert spaces.

\section{Acknowledgments}

This work was supported by the National Science Foundation of China (under Grant 11171221), Shanghai Leading Academic Discipline Project (under Grant XTKX2012), Basic and Frontier Research Program of Science and Technology Department of Henan Province (under Grant 112300410277), Innovation Program of Shanghai Municipal Education Commission (under Grant 14YZ094), Doctoral Program Foundation of Institutions of Higher Education of China (under Grant 20123120110004), Doctoral Starting Projection of the University of Shanghai for Science and Technology (under Grant ID-10-303-002), and Young Teacher Training Projection Program of Shanghai for Science and Technology.

\section{References}

[1] C. Byrne, "Iterative oblique projection onto convex sets and the split feasibility problem," Inverse Problems, vol. 18, no. 2, pp. 441453, 2002.

[2] F. Deutsch, "The method of alternating orthogonal projections," in Approximation Theory, Spline Functions and Applications, vol. 356, pp. 105-121, Kluwer Academic Publishers, Dordrecht, The Netherlands, 1992.

[3] Y. Censor, "Parallel application of block-iterative methods in medical imaging and radiation therapy," Mathematical Programming, vol. 42, no. 2, pp. 307-325, 1988.

[4] G. T. Herman, Image Reconstruction from Projections: The Fundamentals of Computerized Tomography, Academic Press, New York, NY, USA, 1980.

[5] Y. Gao, "Determining the viability for a affine nonlinear control system," Control Theory and Applications, vol. 26, no. 6, pp. 654656, 2009 (Chinese).

[6] Y. Censor and T. Elfving, "A multiprojection algorithm using Bregman projections in a product space," Numerical Algorithms, vol. 8, no. 2-4, pp. 221-239, 1994. 
[7] Y. Censor, T. Elfving, N. Kopt, and T. Bortfeld, "The multiplesets split feasibility problem and its applications," Inverse Problems, vol. 21, no. 6, pp. 2071-2084, 2005.

[8] Y. Censor, T. Bortfeld, B. Martin, and A. Trofimov, "A unified approach for inversion problems in intensity-modulated radiation therapy," Physics in Medicine and Biology, vol. 51, no. 10, pp. 2353-2365, 2006.

[9] C. Byrne, "A unified treatment of some iterative algorithms in signal processing and image reconstruction," Inverse Problems, vol. 20, no. 1, pp. 103-120, 2004.

[10] Y. Dang and Y. Gao, “The strong convergence of a KM-CQ-like algorithm for a split feasibility problem," Inverse Problems, vol. 27, no. 1, Article ID 015007, 9 pages, 2011.

[11] H. K. Xu, "A variable Krasnosel'skii-Mann algorithm and the multiple-set split feasibility problem," Inverse Problems, vol. 22, no. 6, pp. 2021-2034, 2006.

[12] Q. Yang, "The relaxed CQ algorithm solving the split feasibility problem," Inverse Problems, vol. 20, no. 4, pp. 1261-1266, 2004.

[13] J. Zhao and Q. Yang, "Several solution methods for the split feasibility problem," Inverse Problems, vol. 21, no. 5, pp. 17911799, 2005.

[14] A. Moudafi, "The split common fixed-point problem for demicontractive mappings," Inverse Problems, vol. 26, no. 5, Article ID 055007, 6 pages, 2010.

[15] G. Crombez, "A geometrical look at iterative methods for operators with fixed points," Numerical Functional Analysis and Optimization, vol. 26, no. 2, pp. 157-175, 2005.

[16] Z. Opial, "Weak convergence of the sequence of successive approximations for nonexpansive mappings," Bulletin of the American Mathematical Society, vol. 73, pp. 591-597, 1967. 


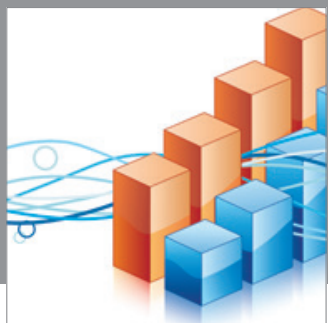

Advances in

Operations Research

mansans

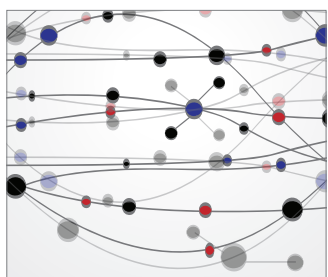

The Scientific World Journal
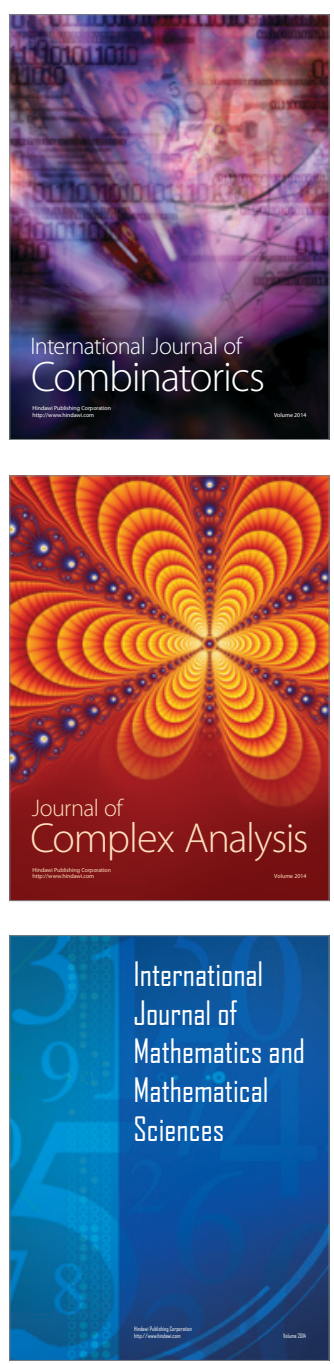
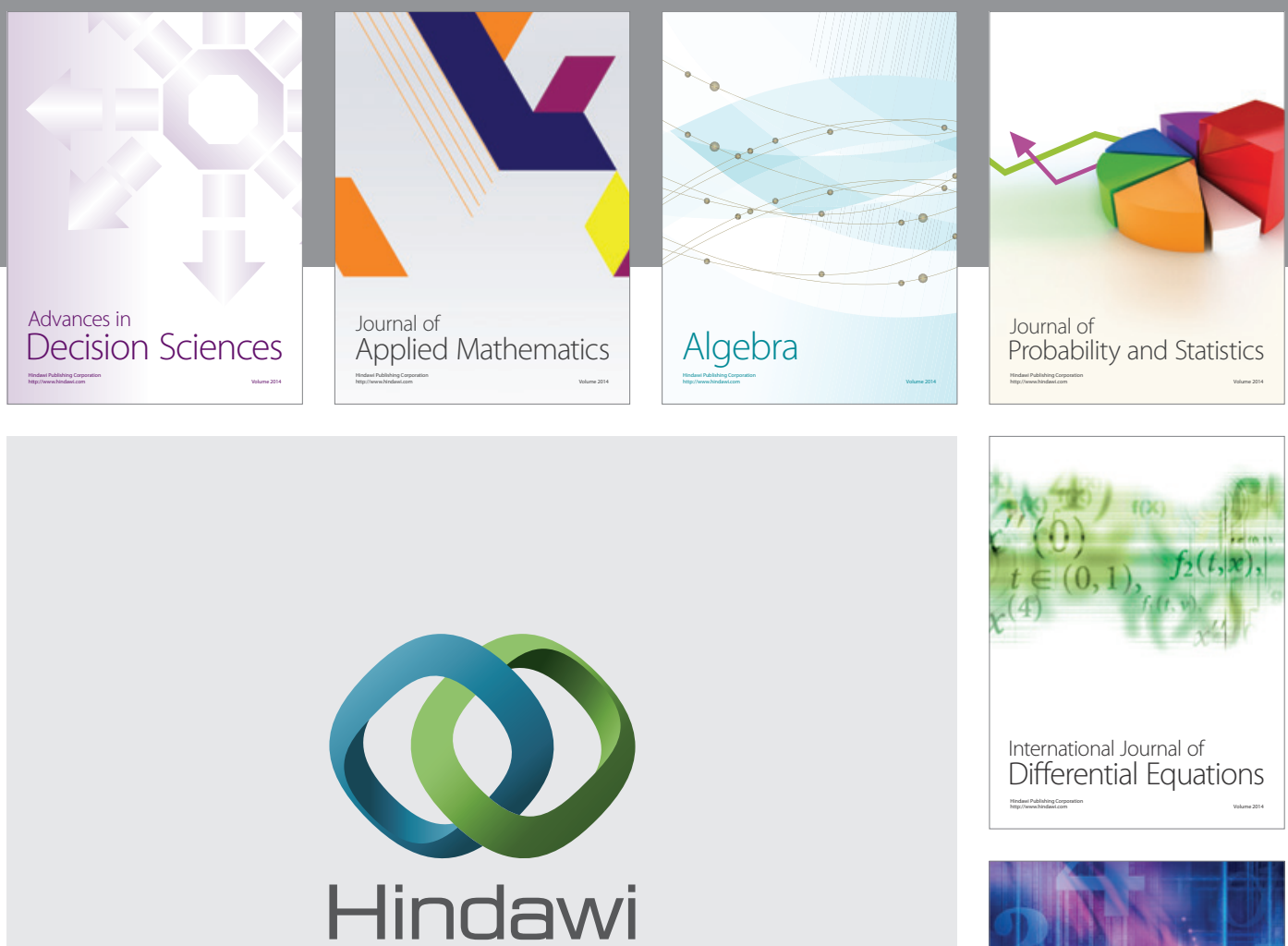

Submit your manuscripts at http://www.hindawi.com
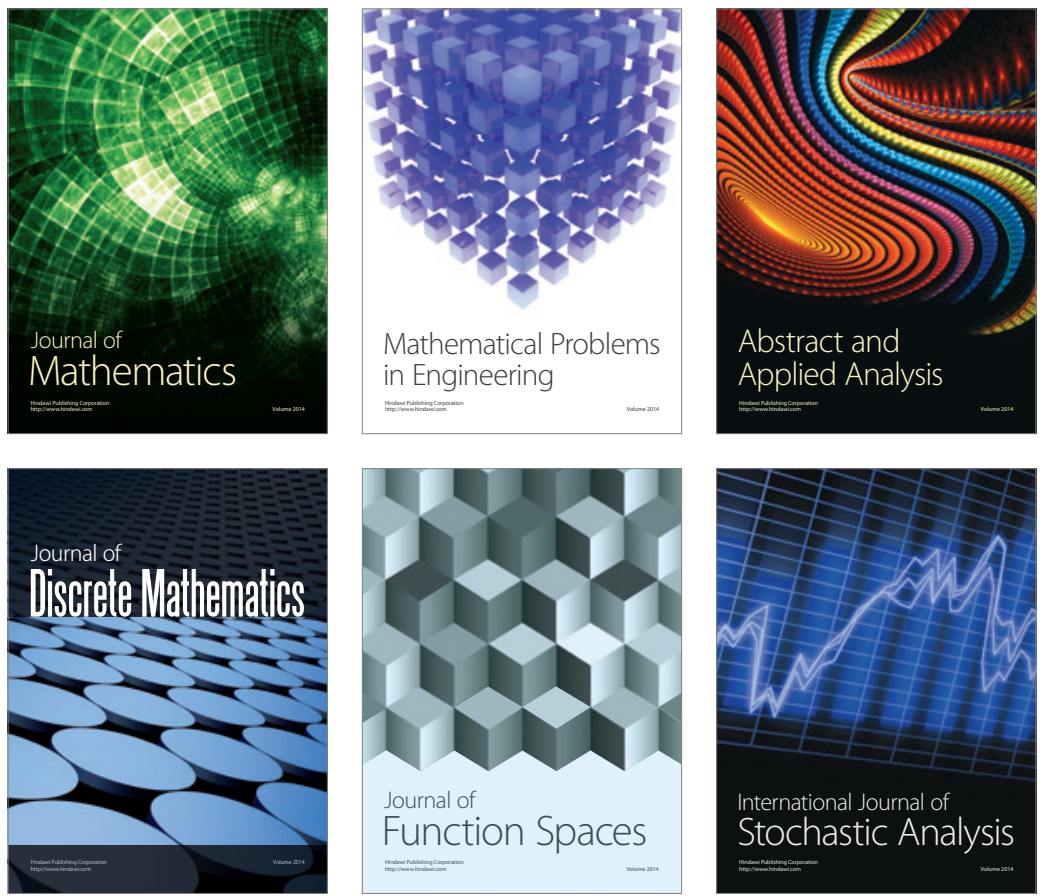

Journal of

Function Spaces

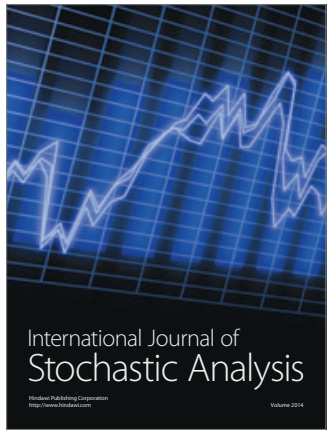

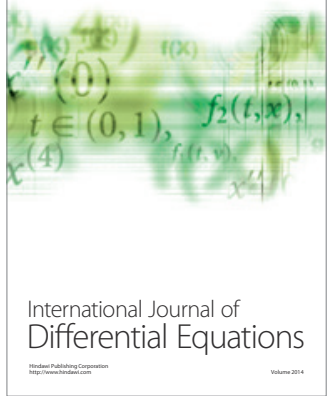
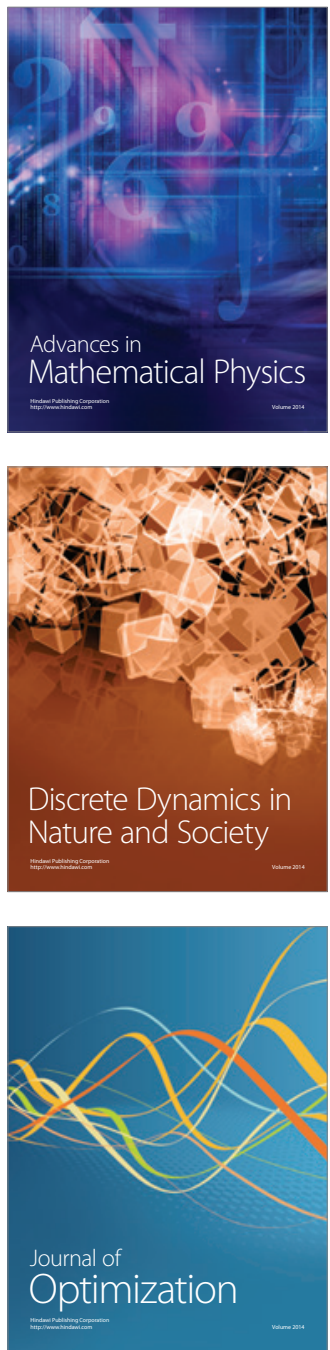